
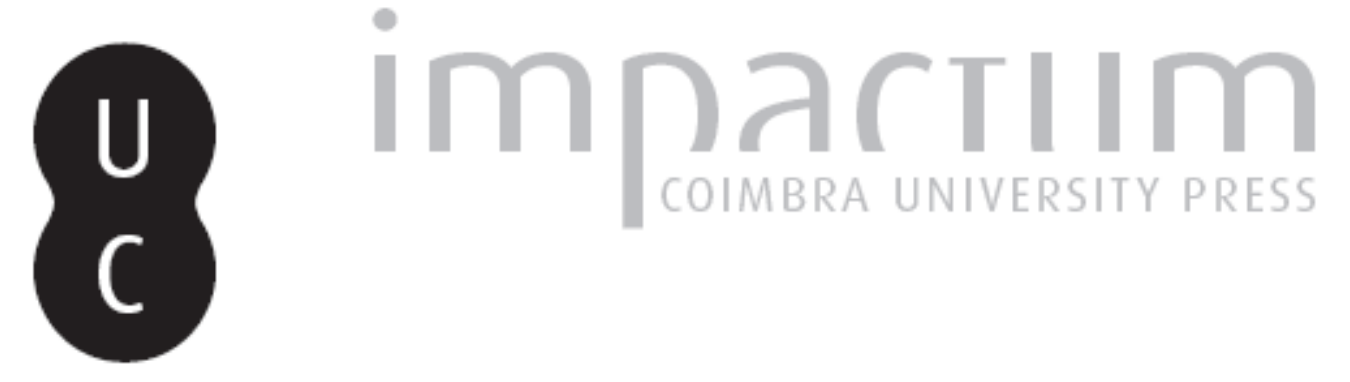

\title{
Em torno da sociologia das ordens militares na Idade Média
}

\section{Autor(es): $\quad$ Oliveira, Luís Filipe}
Publicado por: Faculdade de Letras da Universidade de Coimbra, Instituto de História Económica e Social

URL

persistente:

URI:http://hdl.handle.net/10316.2/33424

DOI:

DOI:http://dx.doi.org/10.14195/0870-4147_44_3

Accessed : $\quad$ 26-Apr-2023 15:16:50

A navegação consulta e descarregamento dos títulos inseridos nas Bibliotecas Digitais UC Digitalis, UC Pombalina e UC Impactum, pressupõem a aceitação plena e sem reservas dos Termos e Condições de Uso destas Bibliotecas Digitais, disponíveis em https://digitalis.uc.pt/pt-pt/termos.

Conforme exposto nos referidos Termos e Condições de Uso, o descarregamento de títulos de acesso restrito requer uma licença válida de autorização devendo o utilizador aceder ao(s) documento(s) a partir de um endereço de IP da instituição detentora da supramencionada licença.

Ao utilizador é apenas permitido o descarregamento para uso pessoal, pelo que o emprego do(s) título(s) descarregado(s) para outro fim, designadamente comercial, carece de autorização do respetivo autor ou editor da obra.

Na medida em que todas as obras da UC Digitalis se encontram protegidas pelo Código do Direito de Autor e Direitos Conexos e demais legislação aplicável, toda a cópia, parcial ou total, deste documento, nos casos em que é legalmente admitida, deverá conter ou fazer-se acompanhar por este aviso.

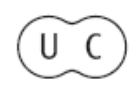




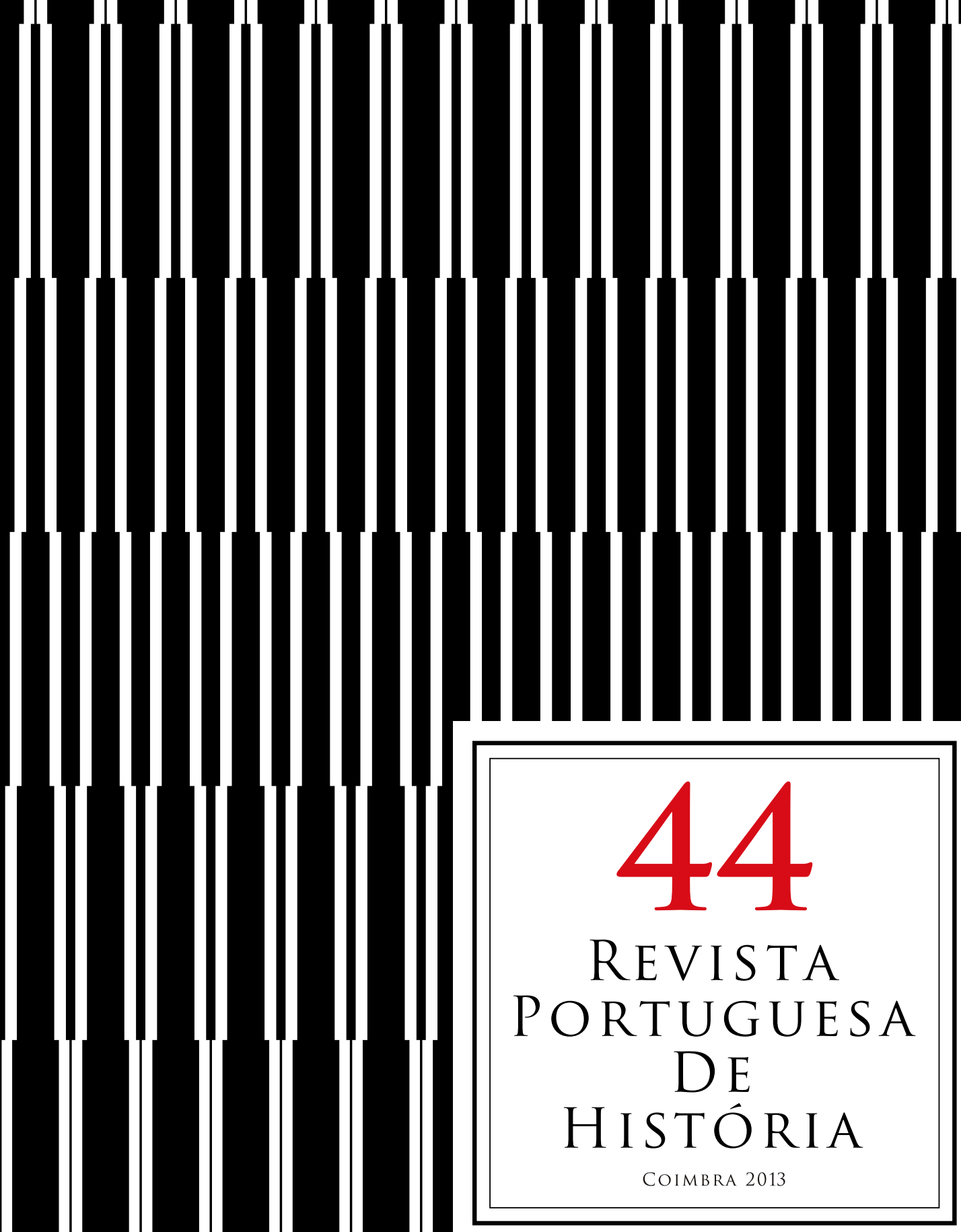




\title{
Em torno da sociologia das Ordens Militares na Idade Média
}

\author{
Luís Filipe OliveIRA \\ I.E.M./ Universidade do Algarve \\ lfolivei@ualg.pt
}

\section{Resumo:}

Com base nos estudos prosopográficos dos últimos anos, ensaia-se neste trabalho uma caracterização da sociologia das ordens militares, que contraria a perspectiva tradicional ao sublinhar a escassez relativa de freires oriundos das famílias nobres e o predomínio daqueles que eram recrutados nos meios urbanos. Revalorizou-se, por isso, a dimensão urbana das ordens militares e insistiu-se na necessidade de estudar o modo como os freires se inseriam nos espaços urbanos, quer nas cidades onde tinham as suas casas de comenda e os seus conventos, quer nas vilas que eles haviam fundado, ou que estavam sob a sua jurisdição. O desinteresse da nobreza pelas ordens militares levou, por outro lado, a que se olhasse para a natureza e a dimensão da clivagem que as separava e se analisassem os processos através dos quais o modo de vida dos monges-guerreiros se aproximou dos valores e dos costumes da aristocracia fidalga. Sem que seja o único factor a ter em conta, pois há que considerar os processos de nobilitação das famílias associadas às ordens, são essas trocas culturais entre a cavalaria leiga e a cavalaria religiosa que podem ajudar a explicar a aristocratização das milícias que se observa durante o século XV.

Palavras chave:

Ordens militares; Nobreza; Élites urbanas; Cavalaria.
Abstract:

Based upon prosopographical data available only on the last years, this work aims to characterize the sociology of the military orders, by emphasizing the relative scarcity of brethren from noble families and the prevalence of those who were recruited among urban groups. This led the author to reassess the urban dimension of military orders and to insist on the need to better study the friars presence in the urban areas where they had their convents and their commanderies, or even their relationship with the small cities which they had found and were under their jurisdiction. On the other hand, by stressing the cultural gap that existed until the mid 14th century between the noble families and the military orders, he calls upon the need to analyze the processes through which the brethren's way of life got closer to the values and customs of the aristocracy. Even though this is not the only factor to be taken in account, as one should also consider the gentrification process of several families associated with the military orders, the cultural exchanges between lay knights and religious knights may help explain why brethren of noble origin became prevalent during the fifteenth century.

Keywords:

Military orders; Nobility; Urban elites; Knighthood.

* Uma primeira versão deste trabalho foi apresentado ao Colóquio Élites et Ordres Militaires au Moyen Age. Rencontre en l'honneur d'Alain Demurger (Lyon, 21-23 Outubro 2009), aguardando publicação nas respectivas actas. 
Nos últimos anos, deram-se passos significativos no conhecimento da composição social das ordens militares. Graças a diversos estudos de natureza prosopográfica, foi possível confirmar, noutras áreas geográficas e para outras ordens, as análises dos historiadores polacos e alemães sobre o recrutamento da Ordem Teutónica ${ }^{1}$. A parte mais substantiva das suas conclusões - isto é, a escassez de freires oriundos da alta nobreza e o predomínio dos recrutas saídos das famílias da pequena nobreza e do patriciado urbano - não estava esquecida, tendo sido acolhida e divulgada por alguns trabalhos de síntese ${ }^{2}$. Faltavam, no entanto, os dados concretos e seguros com que se pudesse dar àquelas observações um alcance mais geral. Foi talvez por essa razão que muitos investigadores continuaram a insistir no predomínio de fidalgos entre os freires, mesmo quando reconheciam não haver indícios para o demonstrar, quer por falta de dados seguros, quer porque estes eram, muitas vezes, de interpretação controversa ${ }^{3}$. A influência das realidades observadas na época moderna, quando as ordens mostram um perfil aristocrático muito acentuado, só dificilmente terá sido alheia a estas opções ${ }^{4}$.

1 Cf. Karol Gorski, "L'Ordre Teutonique: Un nouveau point de vue", Revue Historique, 230 (1963), p. 288-289, 292, 294; Klaus Militzer, "The Recruitment of brethren for the Teutonic Order in Livonia, 1237-1562", in Malcom Barber (ed.), The Military Orders: Fighting for the Faith and Caring for the Sick, Aldershot, 1994, p. 275-277; Johannes A. Mol, "The 'Hospice of the German Nobility': Changes in the Admission Policy of the Teutonic Knights in the Fifteenth Century", in Jurgen Sarnowski (ed.), Mendicants, Military Orders and Regionalism in Medieval Europe, Aldershot, 1999, p. 122-123. Veja-se, também, Kristjan Toomaspoeg, Histoire des Chevaliers Teutoniques, Paris, 2001,p. 48-49; Philippe Josserand, “A Ordem de Santa Maria dos Teutónicos", in Feliciano Novoa Portela e Carlos de Ayala Martínez (eds.), As Ordens Militares na Europa Medieval, Lisboa, 2005, p. 177.

2 Cf.Alan Forey, "Recruitment to the Military Orders (twelfth to mid-fourteenth centuries)", Viator, 17 (1986), p. 143-144, Alan Forey, The Military Order Orders from the Twelfth to the early Fourteenth Centuries, Londres, 1992, p. 133-135; Alain Demurger, Chevaliers du Christ. Les ordres religieux-militaires au Moyen Âge (XI-XVI siècle), Paris, 2002, p. 102-103.

3 Cf. Simon Barton, The Aristocracy in Twelfth-Century León and Castille, Cambridge, 1997, p. 158. Para outras referências ao predomínio de fidalgos entre os freires, Desmond Seward, The Monks of War. The Military Religious Orders, $2^{\mathrm{a}}$ ed. revista [ $1^{\mathrm{a}}$ ed. 1972], Londres, 1995 , p. 17; José Mattoso, Ricos Homens, Infanções e Cavaleiros. A nobreza medieval portuguesa nos séculos XI e XII, 2a edição, Lisboa, 1985, p. 232-236; Stéphane Boissellier, Naissance D'Une Identité Portugaise La vie rurale entre Tage et Guadiana de l'Islam à la Reconquête (X-XIV siécles), Lisboa, 1999, p. 394-395, 406 e nt. 177; Carlos Barquero Goni, "Los Hospitalarios y la Nobleza Castellano-Leonesa (Siglos XII-XIII)", Historia. Instituciones. Documentos, 21 (1994), p. 13-40.

4 Alan Forey, "Rank and Authority in the Military Orders during the twelfth and thirteenth Centuries", Studia Monastica, 40, no 2 (1998), p. 297. Para o predomínio dos nobres entre os freires durante os séculos XV e XVI, veja-se António Pestana Vasconcelos, Nobreza e Ordens 
De um maneira geral, os estudos prosopográficos demonstraram que, nas ordens estabelecidas na Provença, em Castela, em Portugal, ou até na Catalunha, o número de freires nobres só raramente ia além de um terço da amostra $^{5}$. Nem nos conventos centrais do Hospital e do Templo, que foram há pouco estudados, a proporção de nobres era mais significativa. De um total de 144 oficiais - 12 senescales do Templo, 84 comendadores e 48 marechais das duas ordens - apenas $42(29 \%)$ tinham origens fidalgas ${ }^{6}$. Entre estes, alguns provinham de famílias da alta nobreza, se bem que muitos fossem filhos-segundos, ou ilegítimos, mas não eram raros, em contrapartida, aqueles que procediam dos escalões mais baixos da hierarquia fidalga ${ }^{7}$. O panorama não era diferente nas regiões para as quais há dados disponíveis, caso da Hungria, do Norte da Itália, da Provença, da Catalunha e de Castela ${ }^{8}$. Em Portugal, eram de igual modo escassos os professos oriundos das principais famílias nobres da Corte e do Reino, sem que, contudo, fossem mais abundantes os bastardos e os filhos segundos que se encontravam entre eles 9

Militares. Relações Sociais e de Poder (Séculos XIV a XVI), diss. de doutoramento apresentada à F. Letras da Univ. do Porto, Porto, 2008.

5 Cf. Philippe Josserand, "La figure du commandeur dans les prieurés castillans et léonais du Temple et de l'Hôpital: une approche prosopographique (fin XII-milieu XIV siècle)", in Isabel Cristina Fernandes (ed.), Ordens Militares. Guerra, Religião, Poder e Cultura. Actas do III Encontro sobre Ordens Militares, Palmela, 1999, vol. I, p. 167-169; Philippe Josserand, Église et Pouvoir dans la Péninsule Ibérique. Les Ordes Militaires dans le royaume de Castille (1252-1369), Madrid, 2004, p. 383-391; Damien Carraz, L'Ordre du Temple dans la Basse Vallée du Rhône (1124-1312). Ordres militaires, croisades et sociétés méridionales, Lyon, 2005, p. 295-296, 308; Luís Filipe Oliveira, A Coroa, os Mestres e os Comendadores. As Ordens Militares de Avis e de Santiago (1330-1449), Faro, 2009, p. 174 e ss. Dos 88 freires identificados na Catalunha (Pierre Bonneaud, Els hospitalers Catalans a la Fi de L'Edat Mitjana. L'ordre de l' Hospital a Catlunya i a la Mediterrània, 1396-1472, Lleida, 2008, p. 84-93), cerca de metade tinha origens fidalgas, mas só sete provinham de famílias de barões e muitos eram originários de linhagens de cavaleiros empobrecidos.

6 Jochen Burgtorf, The Central Convent of Hospitallers and Templars. History, Organization, and Personnel (1099/1120-1310), Leiden-Boston, 2008, p. 380-381.

7 Ibidem, p. 379-383.

8 Cf. Zsolt Hunyadi, "The social composition of the Military-Religious Orders in the medieval kingdom of Hungary", in Isabel Cristina Fernandes (ed.), As Ordens Militares e as Ordens de Cavalaria entre o Ocidente e o Oriente, Actas do V Encontro sobre Ordens Militares (15 a 18 de Fevereiro de 2006), Palmela, 2009, p. 323-332; Zsolt Hunyadi., The Hospitallers in the Medieval Kingdom of Hungary, c. 1150-1387, Budapest, 2010, p. 20; Elena Bellomo, The Templar Order in North-West Italy (1142-c.1330), Leiden-Boston, 2008, p. 129-147; Damien Carraz, L'Ordre du Temple dans la Basse Vallée du Rhône, cit., p. 115-125, 298-302; Pierre Bonneaud, Els hospitalers Catalans a la Fi de L'Edat Mitjana, cit., p. 88; Philippe Josserand, Église et Pouvoir dans la Péninsule Ibérique, cit., p. 393-395.

9 Cf. Luís Filipe Oliveira, A Coroa, os Mestres e os Comendadores, cit., p. 166-167, 176-179. 
Os dados conhecidos para as ordens militares portuguesas de Avis e de Santiago também revelaram a importância dos comendadores recrutados nos meios urbanos. O facto não era desconhecido e já fora assinalado, quer na Península Ibérica, quer na Provença, quer mesmo na Itália ${ }^{10}$, mas ignorava-se a verdadeira dimensão do fenómeno. Dos 204 comendadores arrolados entre 1330 e 1449 , perto de um terço (27\%) havia sido recrutado nas cidades, embora o número deva pecar por defeito, vista a maior dificuldade em identificá-los nas fontes conhecidas ${ }^{11}$. A maior parte deles procedia de famílias de cavaleiros associadas ao governo das cidades, se bem que houvesse alguns oriundos dos círculos mercantis, ou de famílias há muito vinculadas ao serviço burocrático dos monarcas. Não eram raros, porém, os que tinham origens mais modestas, caso daquele comendador-mor de Santiago que era filho de um sapateiro, ou daquele outro comendador-mor de Avis que descendia de um advogado de uma vila do interior. Também os mestres se recrutavam nos núcleos urbanos, por vezes após terem exercido uma função tão relevante como a de juiz de uma cidade, embora essa tendência estivesse a desaparecer por meados do século XIV ${ }^{12}$.

Com base nos dados portugueses, foi igualmente possível verificar que a aristocratização das milícias foi um processo tardio ${ }^{13}$, já característico do século XV. Até essa época, eram os freires recrutados nas elites urbanas quem dominava as comendas das ordens. A alteração deste panorama deveu-se, em boa parte, a uma modificação do perfil dos mestres, que se detecta a partir de meados do século XIV e se materializou na entrega dos mestrados a vassalos dos monarcas e a homens da Corte, os quais só professavam por altura das eleições respectivas. Na centúria seguinte, essa tendência acentuar-se-ia com a entrega da administração dos mestrados aos infantes da família real. Por via do controle das profissões, os mestres e administradores podiam colocar nas ordens muitos dos seus parentes e criados, facto que acentuou, por certo, o ambiente

${ }^{10}$ Cf. Anthony Luttrell, "Las Órdenes Militares en la sociedad hispánica. Los Hospitalarios aragoneses, 1340-1360”, Anuario de Estudios Medievales, 11 (1981), p. 593; Anthony Luttrell, "The Hospitaller Priory of Catalunya in the Fourteenth Century", in The Hospitaller State on Rhodes and its Western Provinces, 1306-1462, Aldershot, 1999, n XV,p. 7-8; Philippe Josserand, Église et Pouvoir dans la Péninsule Ibérique, cit., p. 396-401; Pierre Bonneaud, Els hospitalers Catalans a la Fi de L'Edat Mitjana, cit., p. 88, 90-93; Damien Carraz, L'Ordre du Temple dans la Basse Vallée du Rhône, cit., p. 125-129, 300-301; Elena Bellomo, The Templar Order in North-West Italy, cit., p. 134-135, 161 e ss.

${ }^{11}$ Cf. Luís Filipe Oliveira, A Coroa, os Mestres e os Comendadores, cit., p. 174-176.

${ }^{12}$ Para tudo isto, veja-se ibidem, p. 59-62, 186-193, 238-241, 437-438.

${ }^{13}$ Ibidem, p. 193-201. Para as observações que seguem, vejam-se as p. 62-79, 113-124, 184-185, 201-211. 
aristocrático das milícias. Mesmo que haja outros factores a ter em conta como a nobilitação de algumas famílias de origem vilã, ou o maior controle que os freires passaram então a exercer sobre os frutos das comendas, ou até sobre a sua provisão - , o peso de tal transformação não deve ser minimizado. Por meados do século XV, já mais de metade dos comendadores era de origem nobre, embora nem então as ordens se tivessem transformado num espaço exclusivamente destinado aos fidalgos do reino.

Seria importante analisar a cronologia deste processo noutras ordens e noutras regiões. Ao que tudo indica, também na Hungria a aristocratização das ordens seguiu uma cronologia muito semelhante e há vários indícios de que o processo não terá sido muito diverso nas ordens castelhanas ${ }^{14}$. Eles não bastam, porém, para dar ao fenómeno um alcance geral. Haveria que dispor de dados fiáveis para outros espaços europeus. Se bem que não se conheça a composição social das milícias durante os séculos XII e XIII, nem o lugar delas nos espaços senhoriais e concelhios, a cronologia que se detectou em Portugal pode corresponder, de facto, a uma particularidade regional, talvez explicável pelo termo precoce das guerras de Reconquista. Como as ordens deixaram de poder fazer a guerra contra os infiéis no território do reino - em 1319, com a fixação da nova ordem de Cristo na fronteira marítima também não se animou a guerra naval contra o infiel —, não terá a profissão nas milícias cessado de atrair os jovens da aristocracia guerreira? Que poderia aliciá-los? $\mathrm{O}$ ideal de serviço à Cristandade? $\mathrm{O}$ serviço do rei, cada vez mais importante para os homens das ordens? A expectativa de uma colocação prestigiada? Ainda que não haja resposta para estas questões, poder-se-ia assim explicar o reduzido número de freires de origem nobre ao longo do século XIV, embora haja indícios de animosidade dos meios nobiliárquicos em relação às ordens, como adiante se verá. Seja como for, torna-se curioso que a aristocratização das milícias seja pouco posterior às guerras com Castela de finais do século XIV, por vezes caracterizadas por uma oposição religiosa muito

${ }^{14}$ Cf. Zsolt Hunyadi, "The social composition of the Military-Religious Orders", cit., p. 326-329; Philippe Josserand, Église et Pouvoir dans la Péninsule Ibérique, cit., p. 401-403; Enrique Rodriguez-Picavea Mattilla, "Prosopografia de la Orden de Calatrava en Castilla: La primera mitad del siglo XV”, Meridies, 7 (2005),p. 201-244; Enrique Rodriguez-Picavea Mattilla, "Caballeros calatravos y linajes castellanos (mediados del siglo XIV-mediados del siglo XV)", in Isabel Cristina Fernandes (ed.), As Ordens Militares e as Ordens de Cavalaria, cit., p. 157-186. Ainda que os dados apresentados por este último Autor datem, por norma, dos séculos XIV e $\mathrm{XV}$, note-se que ele insiste no estatuto aristocrático de Calatrava (Enrique Rodriguez-Picavea Mattilla., "El Processo de aristocratización de La Orden de Calatrava (Siglos XIII-XV), Hispania Sacra, 59, no 120 (2007), p. 493-495) desde as suas origens. 
significativa ${ }^{15}$, ou que seja contemporânea da abertura de uma frente de cruzada em África, através da conquista de Ceuta em 1415.

Mas conviria dispor, também, de dados seguros sobre a importância do recrutamento urbano noutras regiões. Nem sempre a ligação das ordens às cidades e às suas gentes tem sido devidamente valorizada ${ }^{16} \mathrm{e}$ as informações disponíveis são escassas e demasiado circunscritas ${ }^{17}$. Como instituições que tinham sido fundadas em ambientes urbanos e que aí haviam instalado os seus conventos e muitas das sedes das suas comendas, é provável que as ordens tivessem um papel activo em vários dos domínios da vida urbana. Era o que sucedia, por certo, com algumas comendas húngaras do Templo e do Hospital, cujas competências foram usadas, desde meados do século XIII, para validar documentos de natureza privada ${ }^{18}$. Conhecem-se mal os meandros de tal inserção na vida local, e, em particular, as relações de solidariedade e de familiaridade nas quais os freires eram parte ${ }^{19}$, mas os vínculos de vizinhança tinham, como se sabe, um papel decisivo no recrutamento das ordens ${ }^{20}$. Os próprios freires

${ }^{15}$ Para a análise da dimensão messiânica desse conflito, veja-se Maria Garcês Ventura, O Messias de Lisboa. Um estudo de mitologia política (1383-1415), Lisboa, 1992; Maria Helena Coelho, D. João I: o que re-colheu Boa Memória, Lisboa, 2005, p. 242 e ss.

${ }^{16}$ Cf. Alain Demurger, "Les Templiers À Auxerre (XII-XIII Siècles)", in Pierre Boucheron e Jacques Chiffoleau (eds.), Religion et Societés Urbains au Moyen Age. Études offertes à J-L Bigot, Paris, 2000, p. 303-312; Karl Borchardt, "Urban Commanderies in Germany", in Anthony Luttrell e Leon Pressourye (eds.), La Commanderie. Institution des ordres militaires dans l'Occident médiéval, Paris, 2002, p. 297-303; Damien Carraz, L'Ordre du Temple dans la Basse Vallée du Rhône, cit., p. 255-283; Damien Carraz, "Les ordres militaires et le fait urbain en France méridionale (XII ${ }^{\mathrm{e}}-\mathrm{XIII}{ }^{\mathrm{e}}$ siècle)", Moines et religeux dans la ville (XII ${ }^{e}$-XIII ${ }^{e}$ siècle), Cahiers de Fanjeaux, 44 (2009), p. 127-165; Thomas Krämer, "The role of the Military Orders in German and French Towns: Functional Comparisons", in Isabel Cristina Fernandes (ed.), As Ordens Militares. Freires, Guerreiros, Cavaleiros. Actas do VI Encontro sobre Ordens Miitares (10 a 14 Março 2010), Palmela, 2012, vol. II, p. 519-542.

${ }^{17}$ Cf. Damien Carraz, L'Ordre du Temple dans la Basse Vallée du Rhône, cit., p. 125- 129, 295-302; Elena Bellomo, The Templar Order in North-West Italy, cit., p. 159-174; Pierre Bonneaud, Els hospitalers Catalans a la Fi de L'Edat Mitjana, cit., p. 86-88, 90-93; Jochen Schenk, "Aspects of Non-Noble Family Involvement in the Order of the Temple", in Judith Upton-Ward (ed.), The Military Orders: On Land and by Sea, Aldershot, 2008, p. 155-161.

${ }^{18}$ Cf. Zsolt Hunyadi, "The Locus Credibilis in Hungarian Hospitaller Commanderies", in A. Luttrell e L. Pressourye (eds.), La Commanderie, cit., p. 285-296.

${ }^{19}$ Sobre as formas de associação de leigos às milícias, veja-se Francesco Tommasi, "Men and Women of the Hospitaller, Templar and Teutonic Orders", in Anthony Luttrell e Helen Nicholson (eds.), Hospitaller Women in the Middle Ages, Aldershot, 2006, p. 71-88.

${ }^{20}$ Cf. Alan Forey, "Recruitment to the Military Orders", cit., p. 140-141, 170; Damien Carraz, L'Ordre du Temple dans la Basse Vallée du Rhône, cit.,p. 291-294; Luís Filipe Oliveira, A Coroa, os Mestres e os Comendadores, cit., p. 167-170. 
parecem ter cultivado essa proximidade, como testemunha a sua preocupação pelas obras de caridade, sempre mais necessárias nos meios urbanos, ou a sua preferência pelos cultos populares ${ }^{21}$. Entre estes últimos, podem destacar-se os cultos dos Mártires, de S. Braz, de Santiago e da Vera Cruz, todos promovidos pelas ordens. Aquilo que se conhece da geografia e da sociologia de um deles, o dos santos mártires de Lisboa, revela com efeito um padrão urbano bastante acentuado $^{22}$. Um facto ainda mais significativo quando se sabe que o mosteiro de Santos, a casa onde as freiras de Santiago guardavam e cultuavam essas relíquias, também recrutava boa parte das suas professas nas famílias de Lisboa e doutras cidades do reino ${ }^{23}$. Em Tavira, o culto aos freires mártires caídos durante a conquista, que se inicara, talvez, durante o século XIII, haveria de transformar-se, por finais da época medieval, no principal culto cívico da cidade $^{24}$.

É provável que a sintonia com o mundo urbano fosse, assim, bastante significativa. É o que sugere, por exemplo, o testemunho de um comendador de Santiago em 1328, quando declarou estar disposto a usar o corpo e os amigos para defender os interesses dos habitantes de duas vilas portuguesas ${ }^{25}$, ambas situadas nos arredores de Lisboa. As notícias deste teor não são, infelizmente, muito abundantes, mas eram frequentes as relações amigáveis entre os freires e as gentes das cidades ${ }^{26}$. O indício mais eloquente encontra-se, no entanto, na significativa inclusão de um mercador entre os freires mártires da conquista de Tavira, que se lê na Crónica de Portugal de $1419^{27}$, numa passagem por certo baseada na crónica perdida de Paio Peres Correia, o mestre de Santiago entre

${ }^{21}$ Cf. Helen Nicholson, Templars, Hospitallers and Teutonic Knights. Images of the Military Orders, 1128-1291, Leicester, 1995, p. 116-122; Alain Demurger, Chevaliers du Christ, cit., p. 186-191; Philippe Josserand, Église et Pouvoir dans la Péninsule Ibérique, cit., p. 147-163. Sobre a Vera Cruz e o seu culto em Portugal, veja-se Luís Krus, A Concepção Nobiliárquica do Espaço Ibérico (1280-1380), Lisboa, 1994, p. 129 e ss.

${ }^{22}$ Cf. Odília Gameiro, "Sociologia e geografia do culto medieval dos Santos Mártires de Lisboa", in Luís Krus, Luís Filipe Oliveira, João Luís Fontes (eds), Lisboa Medieval. Os rostos da cidade, Lisboa, 2007, p. 371-387; Luís Filipe Oliveira, "O mosteiro de Santos, as freiras de Santiago e o culto dos Mártires", in Maria Themudo Barata, Luís Krus (eds.), Olhares sobre a História. Estudos oferecidos a Iria Gonçalves, Lisboa, 2009, p. 429-436.

${ }^{23}$ Cf. Luís Filipe Oliveira, "Uma barregã régia, um mercador de Lisboa e as freiras de Santos”, in L. Krus, L. F. Oliveira, J. L. Fontes (eds.), Lisboa Medieval, cit., p. 182-196.

${ }^{24}$ Cf. Pedro Picoito, "Os Sete Mártires de Tavira. História de um culto local”, V Jornadas de História de Tavira. Actas, Tavira, 2006, p. 52-70.

${ }^{25}$ Arquivo Municipal de Sesimbra, CMS/D/01, Lv. 01, fls. 9 e v. (de 4-IV-1328).

${ }^{26}$ Cf. Luís Filipe Oliveira, A Coroa, os Mestres e os Comendadores, cit., p. 165 (nt. 85), 197-198.

${ }^{27}$ Crónica de Portugal de 1419, ed. crítica com introdução e notas de Adelino Calado, Aveiro, 1998, p. 153-154. 
1242 e $1275^{28}$. Com a recordação do martírio de um mercador, associando por esta forma aquele grupo a uma memória de santidade, era como se quisesse revalorizar um dos corpos sociais mais ligados à afirmação das cidades. De certa forma, era essa mesma sintonia que recordavam, também, os homens das cidades do Báltico, quando insistiam na importância dos mercadores na fundação da Ordem Teutónica, ou quando sublinhavam o seu próprio papel, ao lado dos freires, na conquista e na colonização da Prússia ${ }^{29}$.

Mas a presença dos freires nas cidades podia ter outras implicações. De acordo com os dados disponíveis para a Provença, era nos arrabaldes das vilas, em regra com bons acessos e com maior dinamismo económico, que se localizava a maior parte das casas das comendas ${ }^{30}$. Nalguns desses casos, as construções ordenadas pelos freires transformaram-se num pólo ordenador desses espaços, com efeitos no redesenho dos eixos viários, na criação de espaços livres junto às comendas, ou mesmo na organização de lotes para construção ${ }^{31}$. Não eram casos isolados e há outros exemplos ${ }^{32}$, mas nada há de semelhante para o reino português. É provável, contudo, que a capacidade de atracção de algumas casas de comendas fosse suficiente para condicionar, ou influenciar, pelo menos, a ordenação do espaço urbano. Devia ser esse o caso das comendas de Évora e de Arruda no século XIII, cujas igrejas veriam a sua actividade drasticamente reduzida - removeu-se o sino da primeira e proibiu-se a segunda de assistir os fiéis da vila - , pela reacção do bispo de Évora e do prior de S. Vicente de Lisboa $^{33}$. Em Évora, onde a casa dos freires era vizinha da Sé Catedral, o conflito

${ }^{28}$ Sobre esta crónica, veja-se Derek Lomax, "A Lost Medieval Biography: The Corónica Del Maestre Pelayo Pérez”, Bulletin of Spanish Studies, 38 (1961), p. 153-154; Luís Krus, "Crónica da Conquista do Algarve", in Giulia Lanciani e Giuseppe Tavani (eds.), Dicionário da Literatura Medieval Galega e Portuguesa, Lisboa, 1993, p. 176; Daniel Rodriguez Blanco, "Pelay Pérez Corea. Entre la Historia y la Leyenda", in Manuel González Jiménez (ed.), Sevilla 1248. Congreso Internacional Conmemorativo del 750 Aniversario de la Conquista de la Ciudad de Sevilla por Fernando III, Rey de Castilla y León (Sevilla, Real Alcázar, 23-27 de Noviembre de 1998), Madrid, 2000, p. 207-220; Philippe Josserand, "Portrait de maître en héros croisé: la chronique perdue de Pelayo Pérez Correa", in Martin Nejedly e Jaroslav Svatek (eds.), Histoire et mémoire des croisades à la fin du Moyen Âge (Prague, 2008), Toulouse, 2012, p. 89-102.

${ }^{29}$ Cf. Alain Demurger, Chevaliers du Christ, cit., p. 269.

${ }^{30}$ Cf. Damien Carraz, L'Ordre du Temple dans la Basse Vallée du Rhône, cit., p. 259 e ss.

${ }^{31}$ Ibidem, p. 274-278.

${ }^{32}$ Cf. Robert Vinas, "Lotissement", in Nicole Bériou e Philippe Josserand, Prier et Combattre. Dictionnaire européen des ordres militaires au Moyen Âge, Paris, 2009, p. 562-563; Kristjan Toomaspoeg," "Ville", Ibidem, p. 964-966; Alain Demurger, "Villeneuve”, Ibidem, p. 966-967.

${ }^{33}$ Cf. Hermínia Vilar, “A Diocese de Évora e a Ordem de Avis. Dois poderes em confronto na centúria de Duzentos", in Isabel Cristina Fernandes e Paulo Pacheco (eds.), As Ordens Militares em Portugal e no Sul da Europa. Actas do II Encontro sobre Ordens Militares, Palmela, 1997, 
só se resolveria anos mais tarde, quando a Coroa os transferiu para a vila de Avis, cujo nome eles cedo adoptaram ${ }^{34}$. Nas vilas sob jurisdição das milícias, estas tiveram, em contrapartida, um importante papel na difusão do urbanismo de planta regular. Dos casos estudados, há que destacar as vilas templárias de Nisa e de Tomar, mas também a de Sines, que foi urbanizada no século XIV e que pertencia à ordem de Santiago ${ }^{35}$. Talvez se lhes possam juntar outras vilas, como Coina e as zonas portuárias de Sesimbra e de Alcácer ${ }^{36}$, todas sob jurisdição dos freires de Santiago, ou mesmo o espaço intra-muros de Avis ${ }^{37}$, igualmente caracterizado por um traçado regular.

Tais exemplos não podem fazer esquecer aquilo que se ignora sobre a implantação e a morfologia dos conventos e das casas das comendas noutras vilas e cidades, especialmente quando a sua localização não coincidia com os castelos respectivos. Os conventos têm sido maioritariamente estudados pelo seu valor artístico e arquitectónico ${ }^{38}$, facto que tem contribuído para os isolar dos respectivos contextos urbanos, sem que nada se saiba, por outro

p. 271-284; Carlos Silva Tarouca, “As Origens dos Cavaleiros de Évora (Avis) segundo as Cartas do Arquivo da Sé de Évora”, A Cidade de Évora, 5, no 13-14 (1947), p. 30-31, doc n II; Luís Filipe Oliveira, "O mosteiro de Santos, as freiras de Santiago e o culto dos Mártires", cit., p. 431.

${ }^{34}$ Cf. Hermínia Vilar, D. Afonso II. Um rei sem tempo, Lisboa, 2005, p. 131-133; Luís Filipe Oliveira, "Convento de São Bento de Avis", in Bernardo Vasconcelos e Sousa (dir.), Ordens Religiosas em Portugal. Das Origens a Trento - Guia Histórico, Lisboa, 2005, p. 491-493.

${ }^{35}$ Cf. Manuel Sílvio Conde, Tomar Medieval: O Espaço e os Homens, Cascais, 1996, p. 86-87; Luísa Trindade, Urbanismo na composição de Portugal, diss. de doutoramento apresentada à F. Letras da Univ. de Coimbra, Coimbra, 2009, p. 421-443, 471-490, 503-523. Veja-se ainda Manuel Sílvio Conde, "O urbanismo regular e as ordens religiosas militares do Templo e de Cristo: as vilas novas e a evolução urbana de Tomar na Idade Média", in José Carreiras e Giulia Vairo (eds.), I Colóquio Internacional. Cister, os Templários e a Ordem de Cristo. Da Ordem do Templo à Ordem de Cristo. Os Anos da Transição. Actas, Tomar, 2012, p. 271-300.

${ }^{36}$ Cf. José Augusto Oliveira, Na Península de Setúbal, em finais da Idade Média: organização do espaço, aproveitamento dos recursos e exercício do poder, diss. de doutoramento apresentada à FCSH da Univ. Nova de Lisboa, Lisboa, 2008, p. 144-163; Maria Teresa Pereira, Alcácer do Sal na Idade Média, Lisboa, 2000, p. 91-103.

${ }^{37} \mathrm{Cf}$. Armando Pereira, “Avis, viagem a uma vila medieval”, A Cidade de Évora, $2^{\mathrm{a}}$ série, 3 (1998-1999), p. 31-33, 35.

${ }^{38}$ Entre outros, veja-se Jorge Rodrigues, Paulo Pereira, Santa Maria de Flor da Rosa. Um Estudo de História de Arte, Crato, 1986; Paula Pinto Costa, Lúcia Rosas, Leça do Bailio no tempo dos Cavaleiros do Hospital, Lisboa, 2001; José António Macedo, Mosteiro de S. Bento de Avis. Bases para uma proposta de Recuperação, diss. de mestrado apresentada à Univ. de Evora, 2 vols, Evora, 1995; Hugo Pombo, Izelina Corte, João Cunha, O Convento de S. Bento de Avis, Lisboa, 2001; Maria Teresa Pereira, "O Convento da Ordem de Santiago em Alcácer do Sal", Actas do $1^{\circ}$ Encontro de História do Alntejo Litoral (18 e 19 de Outubro de 2009), Sines, 2009, p. 142-155; Isabel Cristina Fernandes, "Os conventos da Ordem de Santiago em Palmela", in I. C. Fernandes (ed.), As Ordens Militares e as Ordens de Cavalaria, cit., p. 583-633. 
lado, da estrutura e da localização de muitas das casas sede das comendas ${ }^{39}$. Talvez o seu estudo ajude a compreender o lugar que lhes cabia no desenvolvimento dos núcleos que estruturavam o espaço urbano, ou até o modo como os freires que nelas viviam se inseriam na vida urbana e nos circuitos económicos locais. A circulação de homens, tal como a de bens e de dinheiro, era uma actividade bem conhecida das ordens, embora estejam mal conhecidas as suas diversas implicações no plano local. Há aí, pois, muito a esclarecer, mormente no que respeita às modalidades de inserção das ordens nos espaços urbanos.

Tal dimensão urbana das ordens militares pode explicar, em parte, o divórcio entre elas e a nobreza que se detecta no caso português. No discurso nobiliárquico dos séculos XIII e $\mathrm{XIV}^{40}$, as cidades surgiam, na verdade, como um espaço hostil, especialmente desajustado aos valores, aos costumes e aos comportamentos fidalgos. A opinião era partilhada pelos autores dos Livros de Linhagens, mas também pelos trovadores que compunham para auditórios maioritariamente aristocráticos ${ }^{41}$. Para eles, era nas cidades que se trocava a honra pela riqueza e a fidelidade pela cobiça, sendo aí que a virilidade e a bravura dos guerreiros era posta em causa pelo contacto com os prazeres e com as comodidades mais diversas ${ }^{42}$. De um modo geral, eram essas mesmas máculas que os meios nobiliárquicos censuravam aos cavaleiros das ordens. Pela ambição e pela avareza que os definia - como aquele mestre que metera os dinheiros da ordem numa empresa comercial ${ }^{43}$, ou aquele comendador-mor da ordem de Santiago que só cuidava em "juntar aver" 4 , também eles subvertiam aquelas condutas e valores, pondo em causa a identidade fidalga. Alguns deles eram mesmo acusados de inverterem a hierarquia do sangue e do mérito pessoal,

${ }^{39}$ Para algumas indicações importantes, apenas relativas à Estremadura castelhana, veja-se Aurora Ruiz Mateos, Arquitectura Civil de La Orden de Santiago en Extremadura: La Casa de La Encomienda. Su proyección en Hispanoamérica, Badajoz, 1985.

${ }^{40}$ Cf. Luís Krus, "A Cidade no Discurso Cultural Nobiliárquico (sécs. XIII-XIV), in Maria Ferro Trindade (ed.), A Cidade. Jornadas Inter e Pluridisciplinares. Actas, Lisboa, 1993, vol. II, p. 381-393.

${ }^{41}$ Ibidem, p. 384; Luís Krus, A Concepção Nobiliárquica do Espaço Ibérico, cit., p. 105-111. Sobre os trovadores e os seus auditórios, veja-se António Resende de Oliveira, Depois do Espectáculo Trovadoresco. A estrutura dos cancioneiros peninsulares e as recolhas dos séculos XIII e XIV, Lisboa, 1994, sobretudo as p. 215 e ss; António Resende de Oliveira, "Cortes Senhoriais", in Giulia Lanciani e Giuseppe Tavani (eds.), Dicionário da Literatura Medieval, cit., p. 170-173.

${ }^{42}$ Cf. Luís Krus, "A Cidade no Discurso Cultural Nobiliárquico”, cit., p. 383-384, 388.

${ }^{43}$ Cf. Cantigas d'Escarnho e de Mal Dizer dos Cancioneiros Medievais Galego Portugueses, ed. de Manuel Rodriges Lapa, $2^{a}$ edição, Coimbra, 1970, nº 326.

${ }^{44}$ Ibidem, n 325 . 
como fora o caso de certo freire de Santiago de origens muito humildes e que só subira à comenda-mor da milícia graças à sua perícia nas artes mágicas ${ }^{45}$. A muitos deles, os trovadores negavam, aliás, o direito ao nome, não deixando de recordar, por vezes, a sua fraqueza em combate, e, sobretudo, uma profunda ligação ao mundo da materialidade, evocada pela circulação do dinheiro, pelos saberes técnicos e pela vida doméstica nas casas e comendas ${ }^{46}$. Não admira, pois, que os Livros de Linhagens olhassem os freires com desconfiança e animosidade e registassem a sua procedência de uniões adúlteras, sacrílegas, e, sobretudo, vilãs ${ }^{47}$. Nem que revelassem a indignidade que os caracterizava, caso daquele mestre de Cristo que matou os sobrinhos do senhor que o criara e que o havia armado cavaleiro ${ }^{4}$. Não sendo vistos com bons olhos, nem julgados dignos dos mais altos feitos, compreende-se que não fossem os freires das ordens, mas os fidalgos portugueses, aqueles a quem o conde de Barcelos atribuiu, no seu Livro de Linhagens, a missão profética de regenerarem a cavalaria hispânica e de libertarem a Cristandade da ameaça muçulmana ${ }^{49}$.

Tal como o discurso nobiliárquico sobre a cidade estava a mudar por meados do século XIV, por via do desenvolvimento de uma nobreza urbana e cortesa $\tilde{a}^{50}$, também por essa época principiou a alterar-se a imagem dos freires

${ }^{45}$ Ibidem, $\mathrm{n}^{\mathrm{0}}$ 402. O freire desta cantiga, de nome Paio, foi identificado com Paio Peres Correia, que foi comendador-mor e mestre de Santiago (cf. Elisa Ferreira Priegue, "«Chegou Paio de Maas Artes...» (CBN 1600 = CV 1132)”, Cuadernos de Estudios Gallegos, 31, n 93-95 (1978-1980), p. 361-369), mas o facto de a composição ser muito posterior à época de vida daquele mestre (cf.A. Resende Oliveira, Depois do Espectáculo Trovadoresco, cit., p. 421-422.), sugere que se trata apenas de um qualquer comendador da ordem de Santiago. Veja-se Cláudio Neto, As Ordens Militares na cultura escrita da Nobreza - 1240-1350. Representações nas cantigas de escárnio e de mal dizer, diss. de mestrado apresentada à FCSH da Universidade Nova de Lisboa, Lisboa, 2012, p. 53-63.

${ }^{46}$ Para uma caracterização do lugar dos freires nas sátiras dos trovadores, veja-se Cláudio Neto, As Ordens Militares na cultura escrita da Nobreza, cit.,p. 116-125. Para as duas cantigas que evocam a fraqueza dos freires, ambas respeitantes a hospitalários, veja-se Cantigas d'Escarnho e de Mal Dizer, $\mathrm{n}^{\circ} 423$ e 431.

${ }^{47}$ Bernardo Vasconcelos Sousa, "As Ordens Militares nos nobiliários medievais portugueses", in I. C. Fernandes (ed.), As Ordens Militares e as Ordens de Cavalaria, cit., p. 623-630; Luís Filipe Oliveira, A Coroa, os Mestres e os Comendadores, cit., p. 198-199.

${ }^{48}$ Cf. Livro de Linhagens do Conde D. Pedro. Portugaliae Monumenta Historica. Nova Série, ed. de José Mattoso, Lisboa, 1980, t. II, p. 28 (44 S6).

${ }^{49}$ Cf. Luís Krus, A Concepção Nobiliárquica do Espaço Ibérico, cit., p. 115-116, 137-142, 298-299. Sobre a relação do conde de Barcelos com as ordens militares, veja-se Luís Filipe Oliveira, "Pedro de Barcelos", in N. Bériou, Ph. Josserand (eds), Prier et Combattre. Dictionnaire européen des ordres militaires, cit., p. 701-702.

${ }^{50}$ Cf. Luís Krus, “A Cidade no Discurso Cultural Nobiliárquico”, cit., p. 389-390. Sobre a nobreza urbana e cortesã, veja-se José Mattoso, "Os nobres nas cidades portuguesas da Idade 
entre os fidalgos do reino. Nas refundições do Livro de Linhagens de Pedro de Barcelos, a primeira feita entre 1360-1365, a outra por volta de $1380^{51}$, são já mais abundantes as menções aos cavaleiros das ordens. Muitas delas surgiam agora despidas de qualquer carga negativa, quando não eram, pelo contrário, claramente elogiosas ${ }^{52}$. Era o que sucedia, por exemplo, com alguns priores do Hospital em Portugal, ou com os mestres de Santiago em Castela ${ }^{53}$, todos responsabilizados pela manutenção dos ideais da Reconquista, e, sobretudo, pela guarda e defesa do próprio reino, em particular durante as perturbações do reinado de Pedro I de Castela ${ }^{54}$. De resto, era agora em benefício dos freires das ordens, e, em particular, dos freires do Hospital ${ }^{55}$, que o último refundidor do Livro de Linhagens desenvolvia a missão profética que o conde de Barcelos havia atribuído aos fidalgos portugueses.

Como é evidente, estas observações não são suficientes para explicar o desinteresse da nobreza pelas ordens militares, nem o modo como os valores e comportamentos desta se foram aproximando do ideal de vida dos monges-guerreiros. Ao que parece, o ponto de partida não podia ser mais distante. Ao apostar na conversão dos cavaleiros do século, a regra primitiva do Templo quase que invertera a ideologia cavaleiresca, negando mérito ao heroísmo, à ostentação e à liberalidade aristocrática ${ }^{56}$. O contraste podia ser menor noutras milícias, em particular na de Santiago, cuja regra permitia o matrimónio dos freires e uma actividade tão mundana como a caça, e que apresentava, por isso, uma matriz leiga mais acentuada ${ }^{57}$. Nem assim, porém, ele desaparecia. Mais que a actividade militar, eram as outras funções exercidas pelos freires,

Média”, Portugal Medieval: Novas interpretações, Lisboa, 1985, p. 273-291; Leontina Ventura, D. Afonso III, Lisboa, 2006, p. 172-195.

${ }^{51}$ Cf. Livro de Linhagens do Conde D. Pedro, cit., t. I, p. 47-60; José Mattoso, “A transmissão textual dos livros de linhagens", in Naquele Tempo. Ensaios de História Medieval, vol. 1 das Obras Completas de José Mattoso, Lisboa, 2000, p. 285 e ss.

${ }^{52}$ Cf. Luís Filipe Oliveira, A Coroa, os Mestres e os Comendadores, cit., p. 199-201.

${ }^{53}$ Cf. Livro de Linhagens do Conde D. Pedro, cit., t. I, p. 214-217 (21A15), 218-219 (F14-15), 238-257 (G14-15).

${ }^{54}$ Cf. Luís Krus, A Concepção Nobiliárquica do Espaço Ibérico, cit., p. 235-236 e nt. 573. Para a análise do papel político dos mestres em Castela, veja-se Philippe Josserand, Église et Pouvoir dans la Péninsule Ibérique, cit., p. 554-555; Luis Diaz Martin, "Los maestres de las ordenes militares en el reinado de Pedro I de Castilla”, Hispania, 40, nº 145 (1980), p. 285-356.

${ }^{55}$ Cf. Luís Krus, A Concepção Nobiliárquica do Espaço Ibérico, cit., p. 137-142.

${ }^{56}$ Cf. Simonetta Cerrini, La Révolution des Templiers. Une histoire perdue du XII siècle, Paris, 2007, p. 135-188; Alain Demurger, Chevaliers du Christ, cit., p. 181-182.

${ }^{57} \mathrm{Cf}$. Jean Leclercq, "La vie et la prière des chevaliers de Santiago d'après leur règle primitive", Liturgica, Montserrat, 2 (1958), p. 347-357; Derek Lomax, La Orden de Santiago (1170-1275), Madrid, 1965, p. 90-100 e doc. $\mathrm{n}^{\mathrm{o}} 1$ do Anexo. 
em regra de natureza monástica e religiosa, que atraíam a atenção dos autores dos poemas épicos e dos romances de cavalaria dos séculos XII e XIII ${ }^{58}$. Não era, pois, o modelo do cavaleiro de Cristo aquilo que mais os interessava e lhes prendia a atenção. Para alguns deles, o exercício da cavalaria no mundo era mais agradável a Deus que a profissão numa ordem militar ${ }^{59}$. Para eles, a cavalaria bastava para garantir a salvação e abrir as portas do Paraíso.

A espiritualização da cavalaria pode constituir, no entanto, um bom indício das trocas culturais entre as milícias e a aristocracia. O fenómeno foi há pouco assinalado na Castela da primeira metade do século XIV, quer a partir das obras do infante Juan Manuel, quer com base noutros textos literários, nos quais a luta contra o infiel é vista como uma forma de martírio ${ }^{60}$. O problema não está estudado em Portugal, mas há indícios que revelam uma mesma tendência para sacralizar a cavalaria. Em rigor, era esse o programa de Pedro de Barcelos por meados do século XIV, quando reivindicou a vanguarda da fé para os fidalgos do reino e lhes entregou a missão profética de regenerarem a cavalaria hispânica e de libertarem a Cristandade do jugo muçulmano ${ }^{61}$. Por iniciativa de um prior do Hospital, o projecto seria desenvolvido em favor dos cavaleiros das ordens, antes de ser retomado pela Coroa em inícios do século $\mathrm{XV}^{62}$, uma vez que ela também assumira funções sagradas na defesa da Igreja, do Reino e de toda a Cristandade. Como o serviço da Coroa se confundia com o serviço de Deus, as conquistas no Norte de África podiam ser apresentadas como verdadeiras cruzadas $^{63}$, ao passo que a morte de um cavaleiro ao serviço de um monarca estava em condições de ser interpretada como um autêntico

${ }^{58}$ Cf. Helen Nicholson, Templars, Hospitallers and Teutonic Knights, cit., p. 86-87, 96-97, 204-207; Helen Nicholson., Love, War, and the Grail. Templars, Hiospitallers, and Teutonic Knights in Medieval Epic and Romance, 1150-1500, Boston-Leiden, 2004, p. 100, 187, 204-205.

${ }_{59}$ Cf. Helen Nicholson, Templars, Hospitallers and Teutonic Knights, cit., p. 12-14, 66-67; Helen Nicholson, Love, War and the Grail, cit., p. 204-5, 215.

${ }^{60}$ Cf. Philippe Josserand, Église et Pouvoir dans la Péninsule Ibérique, cit., p. 214-225; Philippe Josserand, "Itinéraires d'une rencontre: les ordres militaires et l'ideal chevaleresque dans la Castille du Bas Moyen Age (XIII-XV siècle)", in Jean-Pierre Sánchez, L'Univers de La Chevalerie en Castille (fin du Moyen Age-début des temps modernes), Paris, 2000, sobretudo as p. 86-88.

${ }^{61}$ Cf. L. Krus, A Concepção Nobiliárquica do Espaço Ibérico, cit., p. 137-142.

${ }^{62}$ Cf. L. F. Oliveira, A Coroa, os Mestres e os Comendadores, cit., p. 73-77.

${ }^{63}$ Cf. L. F. Thomaz e J. S. Alves, "Da cruzada ao Quinto Império", in Francisco Bethencourt e Diogo Ramada Curto (eds.), A Memória da Nação, Lisboa, 1991, p. 81-164; Isabel Cristina Fernandes e Luís Filipe Oliveira," "As Ordens Militares no Reino de Portugal”, in Feliciano Novoa Portela e Carlos Ayala Martínez, As Ordens Militares, cit., p. 151-153. Para um panorama da cronística portuguesa, veja-se Luís Krus, "Historiografia Medieval", in G. Lanciani e G. Tavani (eds.), Dicionário da Literatura Medieval, cit., p. 312-315. 
martírio ${ }^{64}$. Diversos exemplos o comprovam a partir de meados do século XV, sobretudo com mortes ocorridas em cenários de guerra santa em África.

Os intercâmbios faziam-se, pois, nos dois sentidos. Seria importante averiguar a relação das ordens com a difusão do ritual de iniciação de novos cavaleiros e com o maior apreço dos cronistas do século $\mathrm{XV}$ pelos episódios e pelas proezas cavaleirescas ${ }^{65}$. Há alguns indícios do envolvimento dos freires na divulgação dos romances de cavalaria - a tradução para português de uma parte da Demanda do Graal foi realizada por um freire de Santiago, talvez por finais do século XIII, e, uma centúria depois, lia-se a estoria de Galaaz na casa de um prior do Hospital ${ }^{66}-$, mas são, infelizmente, demasiado escassos e a generalização desses romances não parece ser anterior a meados do século $\mathrm{XIV}^{67}$. Talvez o problema se possa resolver através de uma análise da imagem que, por essa época, os mestres e os comendadores projectavam nas crónicas e noutros textos literários, aproveitando os estudos existentes para o espaço europeu, e, sobretudo, para Castela ${ }^{68}$. Ainda que essa imagem esteja sobretudo modelada pela figura do vassalo fiel ${ }^{69}$, é provável que aquela análise revele a assimilação de alguns valores e costumes da aristocracia fidalga. Sugere-o,

${ }^{64}$ Cf. M. L. Rosa, "Mortos-Tidos por Vivos": O tribunal régio e a acapacidade sucessória das «Almas em Glória» (Campanhas Norte-Africanas, 1472-c.1542)", Anais de História de Além-Mar, 6, (2005), p. 9-46.

${ }^{65}$ Para algumas observações, veja-se Albano Figueredo, $O$ ideal de Cavalaria na Crónica da Tomada de Ceuta de Gomes Eanes de Zurara, diss. de mestrado em Literatura Medieval apresentada à Universidade de Coimbra, Coimbra, 1996, p. 9-60; Luís Krus, "Historiografia Medieval", cit.,p. 314. Para o panorama em Castela, Philippe Josserand, Église et Pouvoir dans la Péninsule Ibérique, cit., p. 172-183.

${ }^{66}$ Cf. Ivo de Castro, "Sobre a data da introdução na Península Ibérica do ciclo arturiano arturiano da Post-Vulgata”, Boletim de Filologia, 28 (1983), p. 81- 98; Estoria de Dom Nuno Alvrez Pereyra, ed. crítica da «Coronica do Condestabre», com introdução e notas de Adelino Calado, Coimbra, 1991 p. 8, cap. IV.

${ }^{67}$ Cf. José Mattoso, "Romance", in G. Lanciani e G. Tavani (eds.), Dicionário da Literatura Medieval, cit., p. 589-590.

${ }^{68}$ Cf. Helen Nicholson, Templars, Hospitallers and Teutonic Knights, cit., p. 80-101; Helen Nicholson, Love, War and the Grail, cit., sobretudo as p. 1-31, 187 e ss; Philippe Josserand, Église et Pouvoir dans la Péninsule Ibérique, cit., p. 166 e ss.

${ }^{69}$ Cf. Luís Filipe Oliveira, A Coroa, os Mestres e os Comendadores, cit., p. 81-86. Para uma análise do predominio do ideal de cortesão sobre o de cavaleiro, veja-se José Mattoso, "João Soares Coelho e a gesta de Egas Moniz”, Portugal Medieval: Novas interpretações, cit., p. 409-435. Em Castela, a imagem dos mestres construía-se por referência às suas virtudes heróicas, aos seus dotes cavaleirescos, e, já no século XV, aos seus atributos monárquicos. Veja-se Philippe Josserand, Église et Pouvoir dans la Péninsule Ibérique, cit., p. 172-183, 219-225, 451-454; Carlos de Ayala Martínez, Las órdenes militares hispánicas en la edad media (siglos XII-XV), Madrid, 2003, p. 210-211, 229. 
desde logo, a identificação das milícias como ordens de cavalaria $^{70}$, assim como a montagem de casas mestrais maiores e melhor estruturadas após meados do século XIV, imitando de perto o modelo seguido na casa do rei e dos grandes senhores ${ }^{71}$. Sobretudo entre os mestres, foi então que se divulgou o costume de recorrer a emblemas heráldicos familiares para compor os sinais com que eles se identificavam tanto em vida, como na morte ${ }^{72}$. Datam também desse mesmo período os primeiros testemunhos da preocupação dos freires com a personalização das suas sepulturas, através da encomenda de epitáfios e da instituição de capelas, quer em igrejas das ordens, quer, ainda, em casas dos dominicanos ${ }^{73}$. Por essa época, como mostram os dados para Castela, era por referência ao seu heroísmo e aos seus dotes guerreiros que se construía a imagem social dos mestres ${ }^{74}$, como se eles fossem os melhores cavaleiros do mundo. Entre os mestres, pelo menos, era evidente a assimilação dos valores e dos critérios de distinção social da fidalguia, mas era preciso dispôr de dados semelhantes para os outros membros das milícias para definir, com segurança, a cronologia da difusão dos costumes aristocráticos no seio das ordens.

Mesmo sem poder resolver estes problemas, que exigem investigações dirigidas e mais demoradas, nada sugere que a maior proximidade dos freires com a nobreza e com os seus valores culturais tivesse reflexos imediatos na organização interna das milícias. Através do controle da Coroa sobre a eleição dos mestres, o perfil sociológico destes aristocratizou-se a partir de meados do século $\mathrm{XIV}^{75}$, com a entrega dos mestrados a vassalos do rei e a importantes fidalgos da Corte. $\mathrm{O}$ facto contribuiu para reforçar, por certo, a autoridade dos

${ }^{70}$ Cf. Philippe Josserand, Église et Pouvoir dans la Péninsule Ibérique, cit., p. 207-209.

${ }^{71}$ Cf. Luís Filipe Oliveira, A Coroa, os Mestres e os Comendadores, cit., p. 106-109.

${ }^{72}$ Ibidem, p. 88-90.

${ }^{73}$ Ibidem, p. 223, 239, 254 e nt. 257, 420, 439, 464, 472, 475; Luís Filipe Oliveira, "Gil Martins do Outeiro", in N. Bériou e Philippe Josserand (eds.), Prier et Combattre. Dictionnaire européen des ordres militaires, cit., p. 389. Para Castela, onde o mesmo costume se difundiu, também, no século XIV, tornando-se mais frequente na centúria seguinte, Carlos de Ayala Martínez, Las órdenes militares hispánicas en la edad media, cit., p. 393-397; Olga Pérez Monzon, "Espacio Funerario y Órdenes Militares en La Castilla Medieval", in Isabel Cristina Fernandes (ed.), As Ordens Militares. Freires, Guerreiros, Cavaleiros, cit., vol. II, p. 903-931.

${ }^{74}$ Cf. Carlos de Ayala Martínez, Las órdenes militares hispánicas en la edad media, cit., p. 209-220; Philippe Josserand, Église et Pouvoir dans la Péninsule Ibérique, cit., p. 214-235; Philippe Josserand, "Itinéraires d'une rencontre: les ordres militaires et l'idéal chevaleresque", cit., p. 92-99. Para Portugal, veja-se o estudo de 118 inscrições tumulares (Luís Filipe Pontes, Do mundo da Corte ao mundo da Memória, diss. de mestrado em História apresentada à FCSH da Universidade Nova de Lisboa, Lisboa, 2008, p. 81 e ss.), todas dos séculos XV e XVI.

${ }^{75}$ Cf. Luís Filipe Oliveira, A Coroa, os Mestres e os Comendadores, cit., p. 53-54, 62-71. 
mestres, depressa ampliada com novos poderes delegados pelos capítulos ${ }^{76}$, num processo que se iniciara por finais do século XIII e que afastava as ordens da dimensão corporativa dos primeiros tempos ${ }^{77}$. Nem por isso o exercício dos mandatos se converteu num mero benefício. Alguns dos mestres então eleitos eram guerreiros experimentados, não sendo poucos os que tinham ligações familiares às ordens ${ }^{78}$. E, por finais do século XIV, foi ainda eleito como mestre de Avis um antigo comendador-mor da milícia, que nela havia professado aos 14 anos e que era filho de um advogado de uma vila do interior do reino ${ }^{79}$. A natureza beneficial dos mestrados só se imporá, aliás, a partir dos anos vinte do século XV, com a sua entrega aos infantes da família real, embora isso fosse parte de um projecto de reforma das ordens e de revitalização da cruzada em África ${ }^{80}$. Alguns anos mais tarde, o cronista-mor do reino já julgou adequado tratar da provisão dos mestrados no capítulo em que abordou o pagamento dos vassalos do monarca ${ }^{81}$, certamente por considerar que eram matérias com a mesma natureza.

Ao contrário dos mestrados, os restantes cargos e ofícios mantiveram uma dimensão funcional importante. Apesar do que se tem dito e repetido ${ }^{82}$, pouco sugere que as comendas se tenham convertido em benefícios vitalícios. A normativa das ordens cistercienses não autorizava a provisão das comendas a título vitalício, e, se a prática fora aceite pelos Estatutos de Cristo de 1326 e pelos Estabelecimentos de Santiago do ano seguinte ${ }^{83}$, esse ideal só a espaços

${ }^{76}$ Ibidem, p. 110-113; Isabel Morgado Silva, "A Ordem de Cristo durante o mestrado de D. Lopo Dias de Sousa (1373?-1417)”, Militarium Ordinum Analecta, 1, (1997), p. 37, 71-72. Para o quadro peninsular, veja-se Carlos de Ayala Martínez, Las órdenes militares hispánicas en la edad media, cit., p. 247-248.

${ }^{77}$ Carlos de Ayala Martínez, Las órdenes militares hispánicas en la edad media, cit., p. 199-208; Carlos de Ayala Martínez, "Las Ordenes Militares en el siglo XIII castellano. La consolidación de los maestrazgos", Anuario de Estudios Medievales, 27 (1997), p. 239-279.

${ }^{78}$ Cf. Luís Filipe Oliveira, A Coroa, os Mestres e os Comendadores, cit., p. 62-71, 264-266, 271-273.

79 Ibidem, p. 67-69, 238-248; Maria Cristina Pimenta, "Fernão Rodrigues de Sequeira", in N. Bériou e Ph. Josserand (eds.), Prier et Combattre. Dictionnaire européen des ordres militaires, cit., p. 360.

${ }^{80}$ Cf. Luís Filipe Oliveira, A Coroa, os Mestres e os Comendadores, cit., p. 72-79.

${ }^{81}$ Fernão Lopes, Crónica del Rei Dom Joham I, ed. de A. Braancamp Freire e Wiliam Entwistle, Lisboa, 1977, 2a Parte, Cap. 129.

${ }^{82}$ Entre outros, veja-se Carlos de Ayala Martínez, Las órdenes militares hispánicas en la edad media, cit., p. 243, 246, 347-350; Philippe Josserand, Église et Pouvoir dans la Péninsule Ibérique, cit., p. 337-339.

${ }^{83}$ Veja-se, respectivamente, Joseph O'Callaghan, “The Earliest 'Difiniciones' of the Order of Calatrava, 1304-1383”, Traditio, 17 (1961), p. 255-284, republ. in The Spanish Military 
era respeitado. Até finais do século XIV, pelo menos, a rotação dos freires por várias comendas era um fenómeno frequente e a maior parte dos mandatos de comendador tinha uma duração limitada, em regra inferior a três, ou a cinco $\operatorname{anos}^{84}$. Como recordava a normativa, a acção dos freires numa comenda não fugia ao escrutínio do mestre, dos visitadores e dos capítulos, não sendo raro que eles fossem privados da casa, ou transferidos para uma outra ${ }^{85}$, sem que tais percursos possam ser interpretados como uma carreira, vista a semelhança entre os rendimentos proporcionados pelas várias comendas ${ }^{86}$. Não era maior o controle sobre os réditos respectivos, já que a autorização para disporem de parte deles para fins particulares - em caso de morte, ou para satisfazerem os serviços de criados e de servidores - , apenas se tornará corrente a partir de finais do século XIV ${ }^{87}$. Até essa época, os mandatos de comendador deviam manter, pois, uma importante dimensão funcional. Tal situação só se alteraria no século seguinte, quando começou a ser possível negociar a transmissão de uma comenda entre familiares, se bem que haja que esperar pelos meados da centúria para encontrar o primeiro caso inequívoco de sucessão hereditária numa comenda ${ }^{88}$.

Nada demonstra, por outro lado, que os diferentes ofícios das milícias estivessem sob controlo de algum grupo particular de freires. A comenda-mor, por exemplo, não era apanágio de ninguém, e nela foram providos, ao longo

Order of Calatrava and its Affiliates, Londres, 1975, $\mathrm{n}^{\circ}$ VII, p. 279, $\mathrm{n}^{\circ}$ 37; Isabel Morgado Silva, "A Ordem de Cristo durante o mestrado de D. Lopo Dias de Sousa", cit., p. 32; Isabel Lago Barbosa, "A Ordem de Santiago em Portugal na Baixa Idade Média: normativa e prática", Militarium Ordinum Analecta, 2 (1998), doc. E, p. 234.

${ }^{84}$ Cf Luís Filipe Oliveira, A Coroa, os Mestres e os Comendadores, cit., p. 127-130.

${ }^{85}$ Para alguns exemplos, veja-se Ibidem, p. 124-127.

${ }^{86}$ Cf. Luís Filipe Oliveira, “As Definições da Ordem de Avis de 1327”, in I. C. Fernandes (ed.), As Ordens Militares. Freires, Guerreiros, Cavaleiros, cit., vol. I, p. 378-381.

87 A.M.S., CMS/D/01, Lv. 01, fls. 111 v., 112 (de 19-III-1389); IAN/TT, M.C.O., Ordem de Avis / C. S. Bento, Cx. 14, Mç. 10, nº 913 . O diploma foi promulgado em Dezembro de 1412, data obtida através das cartas régias de confirmação (IAN/TT, M.C.O., Ordem de Avis / C. S. Bento, Cx. 14, Mç. 10, nº 910; Chancelaria de D. João I, Lv. 4, fls. 57 v.-58 v. (ambos de 4-X-1421), das resoluções então tomadas.

${ }^{88}$ Trata-se da comenda da ordem de Avis em Coruche (Luís Filipe Oliveira, A Coroa, os Mestres e os Comendadores, cit., p. 209,316-320), que surge nas mãos de Lopo Dias de Brito a partir de Julho de 1456, depois de ter sido administrada pelo seu pai, Diogo Lopes de Brito entre 1405 e 1446, pelo menos. Para o panorama peninsular, que não é diverso, veja-se Carlos de Ayala Martínez, Las órdenes militares hispánicas en la edad media, cit., p. 352; Daniel Rodríguez Blanco, La Orden de Santiago en Extremadura en la baja Edad Media Media (siglos XIV y XV), Badajoz, 1985, p. 129-132; Maria Bonet Donato, La Orden del Hospital en la Corona de Aragón. Poder y gobierno en la Castellania de Amposta (siglos XII-XV), Madrid, 1994, p. 110. 
do século XIV, quer freires fidalgos, quer freires oriundos das elites urbanas. Entre 1341 e 1351, o comendador-mor de Santiago era filho de um sapateiro de Beja, e, antes de terminar a centúria, a comenda-mor de Avis foi confiada ao filho de um advogado de uma vila do interior ${ }^{89}$. Os exemplos nem sequer se limitavam ao século XIV: entre 1432 e 1451, a comenda-mor de Santiago foi ocupada pelo filho de um antigo servidor da Coroa, que era, aliás, originário de Évora ${ }^{90}$. Posto que a informação seja menos clara, também o Conselho dos Treze da Ordem de Santiago obedecia a um padrão semelhante, sem a natureza oligárquica que lhe foi atribuída ${ }^{91}$. De resto, a sua constituição dependia da vontade do mestre e ninguém, nem mesmo o comendador-mor, tinha nele um lugar cativo ${ }^{92}$. Com base nos dados disponíveis, é provável que a nomeação dos membros do Conselho estivesse apenas determinada pelas qualidades e pelas competências de cada freire, ou pela confiança que os mestres neles depositavam. Mais que a uma qualquer oligarquia existente no interior da ordem, os membros deste Conselho parecem corresponder, pelo contrário, a uma elite de dimensão funcional, sem relação imediata com as distinções sociais existentes no século.

Mesmo que a hierarquia interna não tivesse um conteúdo sociológico preciso e exprimisse, pelo contrário, realidades funcionais, o exercício de um mandato tinha outras implicações sociais. Além das rendas e dos poderes que lhe estavam associados, indispensáveis para distribuir favores entre parentes, criados, e amigos ${ }^{93}$, tal exercício podia ser ocasião para reabilitar e consolidar o poder e o prestígio de uma linhagem. Foi esse o caso dos de Pereira, ou dos

${ }^{89}$ Cf. Luís Filipe Oliveira, A Coroa, os Mestres e os Comendadores, cit., p. 117, 238-243, 437-440; Luís Filipe Oliveira, "Gomes Lourenço de Beja”, in N. Bériou e Ph. Josserand (eds.), Prier et Combattre. Dictionnaire européen des ordres militaires, cit., p. 393-394; Maria Cristina Pimenta, "Fernão Rodrigues de Sequeira", ibidem, p. 360.

${ }^{90}$ Cf Luís Filipe Oliveira, A Coroa, os Mestres e os Comendadores, cit., p. 429-433.

${ }^{91}$ Para os poucos dados disponíveis sobre a composição deste Conselho, veja-se A. de Vargas-Zúñiga (Marques de Siete Iglesias), "Los Trece de la Orden de Santiago. Catalogo Biografico”, Hidlguia, 154-155 (1979), p. 523-597. Para a discussão da sua natureza oligárquica, Daniel Rodriguez Blanco, "La organización institucional de la Orden de Santiago en la Edad Media”, Historia. Instituciones. Documentos, 12 (1985), p. 178-179; Carlos de Ayala Martínez, Las órdenes militares hispánicas en la edad media, cit., p. 318-319; Philippe Josserand, Église et Pouvoir dans la Péninsule Ibérique, cit., p. 392-393, 401; Luís Filipe Oliveira, A Coroa, os Mestres e os Comendadores, cit., p. 131-134, 195-196.

${ }_{92}$ Luís Filipe Oliveira, A Coroa, os Mestres e os Comendadores, cit., p. 132-133.

${ }^{93}$ Para algumas observações, veja-se Bernardo Vasconcelos Sousa, Os Pimentéis. Percursos de Uma Linhagem da Nobreza Medieval Portuguesa (Séculos XIII-XIV), Lisboa, 2000, p. 129-132; Philippe Josserand, Église et Pouvoir dans la Péninsule Ibérique, cit., p. 413-415; Luís Filipe Oliveira, A Coroa, os Mestres e os Comendadores, cit., p. 118-123. 
Pimentéis - deles saíram vários priores da Ordem do Hospital, um mestre de Avis, um comendador-mor de Santiago e vários freires ${ }^{94}-$, e doutros, ainda, como os Correia, os de Avelar e os de Vasconcelos ${ }^{95}$. Mas a profissão numa ordem militar, sobretudo se dava lugar a uma carreira longa e bem sucedida, também podia ser uma porta de acesso à nobreza, ajudando a criar a fama e a honra indispensáveis para quem provinha de meios mais modestos. Foi o que aconteceu, entre outros, com os Mascarenhas, e, em particular, com o mestre de Avis, Fernão Rodrigues, que haveria de ocultar uma origem vilã por detrás de um nome honrado (de Sequeira) e da descendência mítica de um cavaleiro dos tempos da Reconquista ${ }^{96}$.

É possível, de resto, que as ordens militares tenham servido como importantes espaços de osmose social, já que aceitavam a profissão de nobres, de cavaleiros urbanos e de burgueses da cidade, assim reunindo freires com diferentes origens sociais. Para as ordens de Avis e de Santiago, há dados que mostram, pelo menos, a regularidade dos matrimónios entre as famílias nelas presentes, ou destas com outras famílias de origem urbana, ou de procedência fidalga, quer no século XIV, quer mesmo na centúria seguinte ${ }^{97}$. Talvez fosse importante testar tais observações noutras milícias, e, também, noutras áreas geográficas. Caso elas correspondam a uma prática mais generalizada, podem ser um bom indício das trocas culturais que tinham lugar no seio das ordens e

${ }^{94}$ Cf. José Augusto Pizarro, Linhagens Medievais Portuguesas. Genealogias e Estratégias (1279-1325), Porto, 1999.vol. II, p. 302-303, 308-309; Bernardo Vasconcelos Sousa, Os Pimentéis. Percursos de Uma Linhagem da Nobreza Medieval Portuguesa, cit., p. 148-179; Bernardo Vasconcelos Sousa, "Memória familiar e ordens militares. Os Pimentéis no séc. XIV”, in I. C. Fernandes e Paulo Pacheco (eds.), As Ordens Militares em Portugal, cit., p. 37-49; Paula Pinto Costa, "A nobreza e a ordem do Hospital: uma aliança estratégica", in I. C. Fernandes (ed.), As Ordens Militares e as Ordens de Cavalaria, cit., p. 605-621; Luís Filipe Oliveira, A Coroa, os Mestres e os Comendadores, cit., p. 54, 117-118, 222-236, 310,387-388, 490-492.

${ }^{95}$ Cf. José Augusto Pizarro, Linhagens Medievais Portuguesas, cit., vol. II, p. 391-392, 400; Manuel López Fernandez, La Orden de Santiago y el Maestre Pelay Pérez Correa, Ciudad Real, 2001, p. 37 e ss.; Luís Filipe Oliveira, A Coroa, os Mestres e os Comendadores, cit., p. 57-58, 60, 67-70, 118-119, 162, 229-235, 270-276, passim; António Pestana Vasconcelos, "Os Vasconcelos e as Ordens Militares", in I. C. Fernandes (ed.) As Ordens Militares e as Ordens de Cavalaria, cit., p. 247-258.

${ }^{96}$ Cf. Luís Filipe Oliveira, A Coroa, os Mestres e os Comendadores, cit., p. 67-68, 119-120, 184-185, 238-248, 429-433; António Pestana Vasconcelos, "Os Mascarenhas, uma família da Ordem de Santiago", Militarium Ordinum Analecta, 11 (2009), p. 163-180. Para a ligação de outras linhagens às ordens, embora os dados sejam mais tardios e respeitem sobretudo aos séculos XV e XVI, veja-se António Pestana Vasconcelos, Nobreza e Ordens Militares. Relações Sociais e de Poder (Séculos XIV a XVI), cit., p. 221 e ss.

${ }^{97}$ Cf. Luís Filipe Oliveira, A, A Coroa, os Mestres e os Comendadores, cit., p. 181-184. 
ajudar a perceber como o ideal de vida dos freires se pôde combinar com os valores e os costumes das linhagens nobres e dos homens das cidades.

Recebido em/Text submitted on: 21/01/13 Aceite em/Approved on: 10/05/13 